\section{REPRESENTAÇÕES DO CAOS NA MÚSICA DO SÉCULO XVIII ${ }^{1}$}

\author{
Felipe Galhardi \\ Universidade de São Paulo - SP \\ Email: felipe.galhardi.rodrigues@usp.br
}

1. O presente trabalho foi realizado com o apoio da FAPESP - Fundação de Amparo à Pesquisa do Estado de São Paulo (Processo 2016/12137-9).

\title{
Resumo:
}

O Caos tem sido tema de debate constante desde a Antiguidade, embora sejam poucos os estudos que abordem as representaçóes do Caos na música. Obras musicais que imitem o Caos tampouco aparecem em grande quantidade na literatura musical. Contudo, o século XVIII testemunha pelo menos três importantes obras que se propóem a esta tarefa: a abertura Les Elemens (1737), de Jean-Féry Rebel, a abertura da ópera Zaïs (1748), de Jean-Phillippe Rameau e o prelúdio de $A$ Criação (1798) de Joseph Haydn. Ao contrapor as obras, fica claro que, apesar das diferenças estilísticas, elas revelam muitos elementos em comum, tanto no que diz respeito ao uso da matriz clássica, que serve como ponto de partida para todas estas obras, quanto no que se refere às técnicas usadas para exprimir o Caos. Nesse artigo estudaremos as principais compreensóes greco-latinas, seiscentistas e setecentistas acerca do Caos, trilhando o percurso desses pensamentos até os nossos compositores buscando encontrar uma unidade na maneira de se representar o Caos na música do século XVIII.

Palavras-chave: Retórica musical. Poética musical. Música do séc. XVIII. Jean-Féry Rebel. Jean-Phillip Rameau. Franz Joseph Haydn.

\section{Representations of Chaos in $18^{\text {th }}$ Century Music}




\begin{abstract}
:
Chaos has been theme of constant debate since Antiquity, although there are few surveys that approach the representations of it in music. Musical works that imitate Chaos also do not appear in large scale in musical literature. However, the 18th century witnesses at least three important works that go for this duty: the ouverture Les Elemens (1737) by JeanFéry Rebel, the ouverture to the opera Zais (1748) by Rameau and the prelude to The Creation (1798) by Joseph Haydn. It is clear, in comparing them, that, despite of stylistic differences, they reveal many elements in common, both concerning the classics - which serves as starting point to all of these works - and the techniques used by them to express Chaos. In this article, it will be studied the main Greco-latin, seventeenth and eighteenth centuries understandings around Chaos by following the path of these thoughts until those composers, seeking an unity in the way to represent Chaos in eighteenth century music.
\end{abstract}

Keywords: Musical Rhetoric. Musical Poetics. Music in 18th Century. Jean-Féry Rebel. Jean-Phillip Rameau. Franz Joseph Haydn.

\title{
1. O CAOS
}

No decorrer do desenvolvimento da sociedade grega estabeleceram-se diversas regiōes com variaçóes que vão além de diferenças econômicas ou políticas, mas também na pluralidade cultural, religiosa e filosófica. É na Jônia, uma dessas regiōes gregas heterogêneas, que surgem os grandes poemas épicos atribuídos a Homero por volta do século VIII a.C., esó a partir do século VI a.C. surgiriam as primeiras elaboraçóes filosóficas de pensadores como Samos, Éfeso e Mileto. É entre esses dois momentos que se eleva as obras poéticas de Hesíodo, sendo a mais importante delas a Teogonia. Hesíodo é considerado o primeiro autor grego que nos traz de maneira sistematizada a genealogia dos deuses (NIETO, 2000: 25), nessa cosmogonia o poeta coloca o Caos como o princípio gerador de todos os deuses. Nos versos 116 ao 132 encontramos a primeira menção e talvez a mais importante do Caos no poema: 
Sim bem primeiro nasceu o Caos, depois também Terra de amplo seio, de todos sede irresvalável sempre, dos imortais que têm a cabeça do Olimpo nevado, e Tártaro nevoento no fundo do chão de amplas vias, e Eros: o mais belo entre Deuses imortais, solta-membros, dos Deuses todos e dos homens todos ele doma no peito o espírito e a prudente vontade.

Do Caos Érebos e Noite negra nasceram. Da noite aliás Éter e Dia nasceram, gerou-os fecundada unida a Érebos em amor. (HESIODO, 2001, vv. 116-125)

Para Nieto (2000, p. 36), Caos ( $\chi \alpha$ ós) é sinônimo de "Lacuna" $(\chi \alpha ́ \sigma \mu \alpha)$ pois os dois conceitos se relacionam etimologicamente. $\mathrm{O}$ que distinguiria os termos $\chi \alpha ́$ os e $\chi \alpha ́ \sigma \mu \alpha$ seria o nível de generalidade. Pois $\chi \alpha ́ \sigma \mu \alpha$, pode ser qualquer coisa que se configura em uma cavidade, e $\chi \alpha$ ó seria um termo cósmico, pois existiria para os gregos apenas um só Caos (NIETO, 2000, p. 37). Para Torrano (1999, p. 42) uma possível tradu-

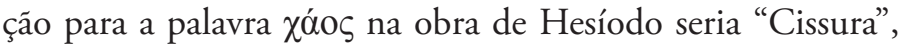
para ele Caos vem do verbo Khaíno ou a variação khásko que significa "abrir-se", "entreabrir-se" ou "abrir a boca".

O Caos está também na obra de Aristóteles, Física (208b), onde écitado o verso 116 do poema de Hesíodo. Contudo, segundo Nieto (2000, p. 28), Aristóteles interpreta o Caos de uma maneira errônea, ele faz a possível conexão entre $\chi \alpha$ ó (Caos) com $\chi \omega ́ \rho \alpha$ (espaço de terra limitado). Essa mesma interpretação aparece também em uma afirmação de Sexto Empírico, autor cético do séc. II d. C.: "'Pois bem, o primeiríssimo que nasceu foi o Caos' porque diz que o Caos é o espaço com capacidade de conter as coisas que existem" (NIETO, 2000, p. 28).

$\mathrm{Na}$ antiguidade romana nos deparamos com duas importantes mençóes ao Caos, a primeira dela é nas Metamorfoses do grande poeta latino Ovídio. O Caos é mencionado logo no início do poema, e assim como nos gregos, ele se relaciona como parte da criação de tudo. Provavelmente foi Ovídio que deu início a outra interpretação possível do Caos como sendo uma massa informe que existia antes da ordenação do mundo (NIETO, 2000, p. 29).

Antes do mar, da Terra, e céu que os cobre não tinha mais que um rosto a Natureza: Este era o Caos, massa indigesta, rude, e 
2. "Porque tú formaste todo el universo a partir de una carência de forma oscura y dispersa. Como si hubieras removido la tumba común de todo el cosmos, expulsaste el caos que lorodeaba hasta los últimos abismos del Tártaro [...] (LUCIANO, 1981, vv. 32) consistente só num peso inerte. Das coisas não bem juntas as discordes[...] (OVÍDIO, 2000, vv. 5-9).

A segunda menção é encontrada na obra de Luciano De Samósata, na obra Amores, porém, é consenso entre todos que essa obra não pertence a Luciano, e sim a um imitador, embora o estilo e os temas usados nos mostrem a influência de Luciano. A obra trata dos tipos de amor, nela são levantadas defesas do amor homossexual e heterossexual.

Pois formastes todo o universo a partir de uma carência de forma, escura e dispersa. Como se removesses a tumba comum de todo o cosmos, expulsaste o caos que o rodeava até os últimos abismos do Tártaro [...] (LUCIANO, 1981, vv. 32, trad. nossa) ${ }^{2}$.

Para Nieto (2000, p. 29), a interpretação usual de Caos que chegou até nós, já pode ser observada em Luciano, que define o termo Caos como matéria desordenada e informe. A descrição do Caos nessa obra de Luciano está bem próxima do Caos descrito em Metamorfoses por Ovídio.

Já nos séculos XVII e XVII podemos observar uma uniformidade ao se definir o Caos, diferentemente dos gregos e dos romanos. Essa uniformidade é facilmente observável ao analisar os verbetes de Caos em dicionários do período, escolhemos três dicionários: Dictionnaire De L'académie Française, Grammatisch-Kritisches Wörterbuch Der Hochdeutschen Mundarte Vocabulario Portuguez\& Latino, os dois primeiros foram selecionados devido a origem dos compositores das músicas analisadas e o último por se tratar do primeiro dicionário da nossa língua.

No Dictionnaire De L'académie Françaiseo verbete Caos está presente em todas as edições do dicionário da academia francesa. Na primeira edição de 1694 já é observável uma definição ovidiana a respeito do Caos, ele é descrito como confusão de todas as coisas antes de deus estabelecer a ordem, ou seja, já é possível estabelecer a palavra Ordem como oposição ao Caos. Na segunda edição, 1718, o Caos aparece com a mesma definição da edição, porém, com o acréscimo que reforça mais ainda a ideia ovidiana, a compreensão do Caos como a confusão de todas as coisas que antecede a criação.

CAOS. s.m. (Não se pronuncia o h,) Confusão de todas as coisas, diz-se que era o estado de todas as coisas no momento 
da Criação, antes que Deus as tivessem alinhado na ordem que agora estão. É também usado para qualquer tipo de confusão. Seus afazeres estão em um caos terrível. Sua biblioteca é um caos (trad. nossa) ${ }^{3}$.Está faltando a nota 3

O dicionário Grammatisch-Kritisches Wörterbuch Der Hochdeutschen Mundart foi uma das maiores realizaçóes de Johann Christoph Adelung, a primeira edição do dicionário tem 5 volumes e foi realizado entre os anos de 1774 a 1786 . Nele podemos encontrar o seguinte verbete:

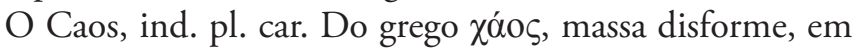
que estavam todos os elementos, antes da formação do mundo, misturados uns aos outros desordenadamente, segundo a criação ensinada pelos poetas gregos e romanos. Figurativamente, uma mixórdia, massa confusa e escura. Seu discurso é para mim um caos incompreensível. Portanto caótico, semelhante ao caos, no mais alto grau de desordem entre si. Rabanus Maurus traduziu o caos como Mihilfinstar, grande escuridão( ADELUNG, 1793, I, 1323, trad. nossa) ${ }^{4}$.

Diferentemente do Dictionnaire de l'Académie française, o verbete Caos do dicionário de Adelung traz consigo a etimologia da palavra, e também explica com mais detalhes, mesmo que equivocadamente, que o Caos era para os gregos e romanos uma massa informe de todos elementos anterior à formação do mundo e desprovida de qualquer ordem, ou seja, uma definição claramente ovidiana.

Por fim, temos a definição do Vocabulario Portuguez\& Latino escrito por Rafael Bluteau entre os anos de 1712 a 1728. Bluteau foi um padre jesuíta, essa sua formação se reflete no seu dicionário, o verbete do Caos é tomado de uma enorme quantidade referências greco-latinas, apesar disso, para Bluteau, o significado figurado de Caos é o mesmo que confusão.

[...] Cá, neste escuro Icaos de confusão, comprindo o curso estou da natureza. Camoens, Soneto 94. Da 2. Centur. Aqui esta palavra confusão parece redundancia, porque o mesmo heconfusão, que Caos, e por isso na Sagrada Escritura se chama o inferno, que todo heconfusaó. Porèm (como judiciosamente advertio Manoel de Faria neste lugar) o intento do Poeta foi dizer o nome, e explicalo para os que podiaó ignorar a significaçaódelle. (BLUTEAU, 1712-1728, p. 116-117)
4. “'Das Chaos, indecl. Plur. Car. aus dem Griech. Xáos, der unförmliche Klumpen, in welchem alle Elemente, vor der Bildung der Welt, ohne Ordnung mit einander vermenget waren, nach der Schöpfungslehre der Griechischen und Römischen Dichter. Figürlich auch, ein Mischmasch, eine verworrene dunkele Sache. Seine

Rede ist für mich ein undurchdringliches Chaos. Daher chaotisch, einem Chaos ähnlich, im hohen Grade unordentlich unter einander. Raban Maurus übersetzt Chaos durch Mihilfinstar, große Finsterniß.” 
Fica claro que já se tornou universal Caos ser sinônimo de confusão, isso é reforçado por todos os autores. Todos citam de alguma forma os versos 7 e 8 de Metamorfoses para justificar esse pensamento. Em seguida veremos como cada um dos nossos compositores tiveram contato com essas compreensóes que os influenciaram na maneira de representar o Caos.

\section{JEAN-FÉRY REBEL}

Não sabemos muito sobre a vida de Rebel, até os anos de 1700 não existem registros sobre sua carreira, podemos supor que ele acompanhou seu pai pelos lugares que ele trabalhou, logo, sua adolescência deve ter sido marcada pelos balés na corte e pelas tragédiesen musique de Lully (CESSAC, 2007, p. 16). Sabemos que em 30 de março de 1718, Rebel passa a dividir o cargo de compositor da Capela Real com Michel Richard de Lalande. Eé muito provável que essa parceria com Lalande tenha influenciado Rebel a compor sua Symphonienouvele, pois em 1721 Michel de Lalande juntamente com André Cardinal Destouches publicaram uma ópera-balé também intitulada Les Élements, essa obra possui um prólogo que faz menção ao Caos, e quatro entrées dedicadas respectivamente ao Ar, à Água, ao Fogo e à Terra. Porém,com exceção de alguns movimentos fluídos em notas ligadas na cena da Água, ou semicolcheias incisivas na do Fogo, segundo Catherine Cessac (2007, p. 104) é inútil procurar nessa obra de Lalande e Destouches, correspondências entre os temas e o tratamento musical.

Na edição de 1725 de LesÉlements de Lalande e Destouches, os autores deixaram indicado de onde eles tiraram suas referências para suas cenas da ópera. Todas essas obras são de autores latinos: Metamorfoses de Ovídio, Nove Livros de Feitos e Dizeres Memoráveis de Valério Máximo e por fim Éclogas e Eneida de Virgílio. Logo, podemos presumir que o Caos concebido por Lalande e Destouches era o Caos ovidiano. Apesar da ópera-balé Les Éléments terem um propósito completamente diferente da obra de Rebel, com certeza ela o influenciou com as suas referências. 


\section{JEAN-PHILIPPE RAMEAU}

Jean-Philippe Rameau, quando criança, estudou no Collègedes Godrans, um colégio jesuíta em Dijon, que hoje em dia se tornou uma biblioteca pública. Ao receber uma educaçáo jesuíta, Rameau, com certeza teve contato com obras gregas e latinas. Conforme o Ratio Atque Institutio Studiorum Societatislesu, obra que organizava e normatizava a pedagogia dos jesuítas nos colégios que os pertenciam. Nesse sistema, os professores eram recomendados trabalhar obras de autores clássicos nas mais diversas aulas.

Além de que foi durante o mecenato de La Pouplinière que Rameau escreve Zaïs, em 1748. Sabemos que Rameau e sua esposa se tornaram muito influentes na casa de La Pouplinière (GIRDLESTONE, 1969, p. 474), com certeza Rameau deve ter tido acesso a biblioteca do seu patrocinador. No qual, segundo o catálogo de livros dessa biblioteca, copilado no ano da morte de La Pouplinière, na seçáo de poetas gregos e romanos, a biblioteca tinha nove títulos de obras do poeta latino Ovídio, onde quatro eram ediçóes diferentes da obra Metamorfoses. Entretanto, a biblioteca não possuia nenhuma obra de Hesíodo, isso deixa bastante claro que a obra de Ovídio era mais difundida no século XVIII em comparaçáo com a de Hesíodo.

\section{JOSEPH HAYDN}

No trabalho de Maria Hörwarthner (1976), onde é recriada a biblioteca de Joseph Haydn, encontramos duas obras de muita relevância para compreender a interpretação de Haydn a respeito do Caos. Essas obras são o Grammatisch-Kritisches Wörterbuch Der Hochdeutschen Mundart e Ovidii Metamorphosisoder Verwandelungs Bücher (1700) de Johann Wilhelm Baur.

O dicionário de Adelung, como já falado anteriormente, têm uma definição do Caos bastante ovidiana. Já o livro de imagens de Wilhelm Baur retrata em gravuras todas passagens míticas de Metamorfoses. É graças a presença dessas obras na biblioteca de Haydn que podemos deduzir que a sua acepçáo de Caos, para Haydn, seja a compreensão ovidiana, o Caos como a confusão dos elementos. Em seguida veremos como 
Rebel, Rameau e Haydn representaram o Caos em suas respectivas obras.

\section{LES ÉLEMENS}

Rebel ao compreender o Caos como confusão dos elementos, ele busca na sua Symphonienouvele representar esses últimos utilizando as convençóes mais comuns (REBEL, 1737, avertissement). A tabela a baixo traz as descriçóes e as representaçóes utilizadas por Rebel para compor sua obra.

\begin{tabular}{|c|c|c|}
\hline $\begin{array}{l}\text { ELEM } \\
\text { ENTO }\end{array}$ & DESCRIÇÃO & REPRESENTAÇÃO \\
\hline Fogo & $\begin{array}{l}\text { Apresentado por } \\
\text { linhas vivas e } \\
\text { brilhantes } \\
\text { representando a sua } \\
\text { vivacidade. }\end{array}$ & $f^{9}+4 \cdots$ \\
\hline $\mathrm{Ar}$ & $\begin{array}{c}\text { Notas longas } \\
\text { seguidas por trinados. }\end{array}$ & (a) \\
\hline Terra & $\begin{array}{l}\text { Notas ligadas } \\
\text { entre si, tocadas como } \\
\text { trêmulos. }\end{array}$ & 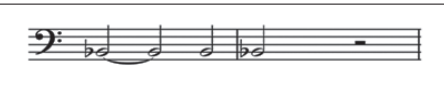 \\
\hline Água & $\begin{array}{l}\text { Linhas melódicas } \\
\text { que sobem e descem. }\end{array}$ & $b=$ की \\
\hline
\end{tabular}

Tabela 1: Representações musicais em LesÉlemens.

\section{ZAÏS}

Rameau deixa bem claro qual é o significado da abertura dessa ópera, "Ouverture, quipeintledébrouillementduCahos", ou seja, ela pinta o desenrolar do Caos. Ao contrário de Rebel, Rameau não deixou escrito como pensou em representar o Caos na sua abertura, e tão pouco indicou no decorrer da partitura possíveis representações de elementos, entretanto ao utilizar as mesmas descriçóes de Rebel em Zaïs encontramos muitas semelhanças. A tabela a baixo traz as descriçóes e as representaçóes encontradas na obra de Rameau: 


\begin{tabular}{|c|c|c|}
\hline ELEMENTO & DESCRIÇÃO & REPRESENTAÇÃO \\
\hline Fogo & $\begin{array}{l}\text { Apresentado por linhas } \\
\text { vivas e brilhantes } \\
\text { representando a sua } \\
\text { vivacidade. }\end{array}$ & 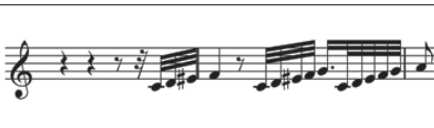 \\
\hline $\mathrm{Ar}$ & $\begin{array}{l}\text { Notas longas, } \\
\text { acompanhadas por trinados. }\end{array}$ & $\frac{+2}{9}$ \\
\hline Terra & $\begin{array}{l}\text { Notas estáticas, tocadas } \\
\text { como trêmulos. }\end{array}$ & 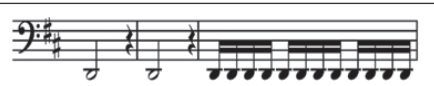 \\
\hline Água & $\begin{array}{l}\text { Linhas melódicas que } \\
\text { sobem e descem. }\end{array}$ & 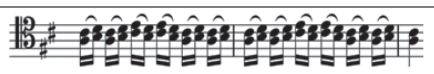 \\
\hline
\end{tabular}

Tabela 2: Representaçôes musicais em Zä̈s.

\section{A CRIAÇÃO}

Haydn em comparação com Rebel e Rameau não é tão explícito em suas intenções para representar elementos na sua obra. Não localizamos muitas figuras musicais que se assemelham a figuras utilizadas por Rebel e Rameau, porém, encontramos uma variedade de outros motivos, o que talvez sugira uma outra forma de representar elementos ou o Caos.

Talvez Haydn tenha optado por representar o Caos de outra forma, visto que a interpretação como confusão dos elementos, uma acepção considerada pagã, não seria adequado para um oratório que narra a criação do mundo e do homem baseado segundo o Gênesis.

\section{CONCLUSÃO}

Dentre todas as fontes que tratam sobre o Caos, percebe-se uma pluralidade de interpretaçóes. Entre os gregos estão Hesíodo, Aristófanes, Aristóteles, e entre os latinos, destacam-se Ovídio e Luciano de Samósata. Contudo, no século XVIII a palavra Caos, graças a grande propagação da obra de Ovídio, Metamorfoses, ganhou duas importantes interpretaçóes: o Caos como sendo a confusão de elementos anterior a criação do mundo para os pagãos; e o Caos como sendo figurativamente sinônimo de confusão. Nas visôes do séc. XVI a XVIII o Caos se associa intimamente aos elementos. Nesta 
pesquisa, foi possível comprovar a importância dos elementos, não apenas para a compreensão do Caos, mas ainda como um riquíssimo repositório de imagens para fundamentar as representações musicais.

Em Les Élemens temos a descrição do próprio Rebel, segundo ele, era inerente que o inicio da sinfonia fosse o Caos, pois era a confusão em que estavam todos os elementos antes que os mesmos ocupassem os lugares que fossem próprios. Rebel se preocupou em qualificar cada elemento em sua música, além de ter deixado indicado na partitura cada elemento. Rameau por outro lado não nos deixou indicado nada que confirmasse a existências de motivos que representassem elementos na abertura da ópera Zaïs, porém, é possivel encontrar uma quantidade de fragmentos que se assemelham muito com os utilizados por Rebel em Les Elemens. Haydn por sua vez também não deixou nada que afirmasse a sua intenção de representar elementos na abertura de $A$ Criação. O Caos se justifica na obra de Haydn por ser interpretado como a confusão primitiva anterior a criação do mundo como conhecemos.

\section{REFERÊNCIAS BIBLIOGRÁFICAS:}

ACADÉMIE FRANÇAISE. Dictionnaire de l'Académie Françoise. Disponível em: https://archive.org/search.ph p?query=creator $\% 3 \mathrm{~A} \% 22 \mathrm{Acad} \% \mathrm{C} 3 \% \mathrm{~A} 9 \mathrm{mie} \% 20$ fra n\%C3\%A7aise\%22. Acesso em 7 jun. 2016.

ADELUNG, Johann Christoph. Grammatisch-kritisches Wörterbuch der HochdeutschenMundart. (1793-1801). Disponível em: http://lexika.digitalesammlungen.de/adelung/ online/angebot. Acesso em 29 abr. 2016.

BLUTEAU, Raphael. Vocabularioportuguez\& latino: aulico, anatomico, architectonico ... Coimbra: Collegio das Artes da Companhia de Jesu, Vol. 8, 1712-1728. Disponível em: http://dicionarios.bbm.usp.br/pt-br/dicionario/edicao/1. Acesso em 1 mai. 2016.

CESSAC, Catherine. Jean-Féry Rebel (1666-1747), musicien des Éléments. Paris: CNRS Éditions, 2007. 
GIRDLESTONE, Cuthbert. Jean-Philippe Rameau: His Life and Work. New York: Dover Publications, 1969.

HAYDN,Joseph. DieSchöpfung.Leipzig: Breitkopfund Härtel [ca.1803]. Disponível em: http://imslp.org/wiki/Die_Sch\%C3\%B6pfung,_Hob. XXI:2_(Haydn,_Joseph) Acesso em 9 jun. 2016.

HESÍODO. Teogonia, a origem dos Deuses. São Paulo: Editoralluminuras Ltda., 2001 (trad. JaaTorrano).

HÖRWARTNER, Maria. Joseph Haydn's Library: An Attempt at a Literary-Historical Reconstruction. In: SISMAN, Elaine (Org.).Haydn and His World. New Jersey: Princeton University Press, 1997.

LALANDE, Michel Richard de; DESTOUCHES, André Cardinal. LesÉlémens. Paris: De l'imprimerie de J-B-Christophe Ballard à Pari, 1725. Disponível em: http://gallica.bnf.fr/ ark:/12148/btv1b9062777j.r=les\%20elemens?rk=85837;2. Acesso em 21 abr. 2017.

LUCIANO. Obras I. Madri: Editora Gredos, 1981 (trad. Alfonso Martínez Díez).

Obras III. Madri: Editora Gredos, 1990 (trad. Juan Zaragoza Botella).

NIETO, Roxana B. Martínez. La Aurora Del PensamientoGriego. Madri: Editora Trotta, 2000.

OVÍDIO. Metamorfoses. São Paulo: Editora Hedra Ltda., 2000 (trad. Manuel M. B. du Bocage).

RAMEAU, Jean-Philippe. Zaïs. Paris: Durand, 1911 [1748].

Disponível em: http://imslp.org/wiki/Za\%C3\%AFs,

RCT_60_(Rameau,_JeanPhilippe). Acesso em 09 jun. 2016.

REBEL, Jean-Féry. Les Élemens. Paris: Le Clerc, 17--? [1737]. Disponível em: http://imslp.org/ wiki/Les_\%C3\%A91\%C3\%A9ments_(Rebel,_ JeanF\%C3\%A9ry). Acesso em 09 jun. 2016. 